\title{
GOVERNMENT-CITIZEN COMMUNICATION IN RURAL MUNICIPALITIES IN LATVIA
}

Zenija Kruzmetra1, Dr.geogr., assist.prof.; Dina Bite 2, Dr.sc.soc., assoc.prof.; Ginta Kronberga ${ }^{3}$, Dr.sc.soc., assist.prof.

1, 2, 3 Latvia University of Life Sciences and Technologies

\begin{abstract}
Government-citizen communication is a prerequisite for the place development and sustainable development. The latest communication theories emphasize the responsibility of local authorities to build communication with local people, to develop safe and sustainable communities, to provide services and infrastructure, to develop horizontal communication networks to promote community development and trust and reduce social distances between social agents. The aim of the article is to explore government-citizen communication in rural municipalities of Latvia from the viewpoint of local citizens. Tasks are related to describing of theoretical statements concerning governance-citizen communication in the light of sustainable development and analysing empirical information. Results of the research indicate average estimation of the communication with local government and the significance of informal communication networks in rural communities. Though municipalities in rural areas use different communication channels, including modern solutions, the situation analysis reveals a certain discrepancy with theoretical concepts and other research results, because rural municipalities in Latvia are more characterized by a "top-down" communication model, which is often based on power relations, is one-sided and formal. Government-citizen communication in rural municipalities of Latvia is regarded as an up-to-date, but insufficiently identified and evaluated tool for the development of citizens' involvement and place development processes. Therefore, further investigation and exploring are necessary to improve understanding of government - citizen communication and establishing of horizontal cooperation ties.
\end{abstract}

Key words: governance, communication, sustainable place development.

JEL code: R50

\section{Introduction}

The idea of sustainable development, both globally and locally, remains an important theoretical paradigm for research into the development of society. Participation, stakeholders' approach to policy making and its implementation, the use of public and private resources as well as the use of general knowledge and skills in the development of society are prerequisities for sustainable development. Communication and information play an important role since, in the context of sustainable development, it ensures mutual interaction between different development factors, improves the exchange of knowledge and information and, in general, facilitates the involvement of stakeholders (Servaes, 2013).

In the framework of sustainable development, we need to improve communication and links between different social agents: policy makers, representatives of civil society (e.g. representatives of the NGO sector, representatives of formal and informal social movements), local people, academics, communication professionals, and technical field specific professionals. In today's society, as Rico Lie and Jan Servaes reveal, "there is a demand for building knowledge and communication networks and to attach importance to stakeholder interactions and knowledge systems approaches" (Lie, Servaes, 2015).

There are different theoretical approaches that define communication, but they all incorporate the following basic elements of communication: 1) the originator, 2) the recipient, 3) the type of communication, 4) the message and 5) the effect (Bruce, Yearley, 2016). Communication can be viewed as an interactive and open process between different social agents, but the information is linked to certain causal relationships: using messages (cause) to influence or change the recipient's attitude or behavior (effect). Communication is a comprehensive concept, because it involves the 
interaction of people - interpersonal relationships, as well as one-way (linear flow) and two-way flow, or dialogue. The communication process refers to a circular communicative flow (dialogue) in which specific results is not necessarily defined in advance (Mefalopulos, 2008).

There are various communication theories - "diffusion of innovations theory", "extension approaches", or "two step flow", which are quite similar to the theory of modernization, which points out elitist, as well as vertical and downward orientation of the diffusion model. Communication studies reveal that although community groups can obtain sufficiently comprehensive information from impersonal sources such as radio, television and the Internet, this information is relatively modest in influencing their behavioral changes. Similar studies allow us to conclude that information is extracted directly from interpersonal contacts and from mass communication based on them. At the lowest (local) level, before people can consider, discuss and solve problems, they must be aware of the facts and relevant information provided by various media at the national, regional and local levels (Servaes, Malikhao, 2005).

Local authorities as communication agents are responsible for involving stakeholders in communication, all the more so nowadays, when digital media offer great opportunities for interconnection and dialogue with local people. For local people, the municipality can effectively provide quality services through e-government tools that allow feedback and dialogue. Various, relatively easy-to-use platforms allow citizens to access and use information, receive services, keep up-to-date on a regular basis. In view of these aspects, rural municipalities are faced with a range of challenges to provide citizens with growing demand concerning e-management and the quality of services through online tools and two-way flow of information with limited resources. However, despite the fact that ensuring good governance is a primary task for municipalities, for in order to build a safe and sustainable community of daily life, municipalities must constantly maintain and improve their services, infrastructure and knowledge of local people's needs (Kagume, 2015).

Local authorities, as important social agents, should initiate social communication and information transfer, thus creating preconditions for reaching mutual agreement between the parties, as the power of local authorities is based on communication and understanding of the needs of the parties involved, thus increasing the community activity (Smalec, 2015).

Local authorities, in the exercise of their functions, must take into account the needs of citizens, have access to them, guarantee confidentiality, and provide high-quality services. The needs of stakeholders are different, hence communication plays a crucial role in fully understanding the different needs of stakeholders and harmonizing the necessary actions. As a society develops, a citizen who was more characterized in the past with the role of citizen-petitioner, now has a citizen-client relationship with a local government. Mutual trust and profitability make it possible to improve, transform and adapt services provided by the municipality to meet market needs and social change. Conscious of the needs of citizens and clients, local government officials do not only play their traditional role, but also become client advisers; in some respects, the official becomes a public affairs manager. Citizens who are satisfied with the services received will also have a good opinion of the activities of the municipality, which in turn will have a positive impact on the municipality's image. Communication between the municipality and the local population can be assessed through feedback and the level of satisfaction of the received services, since it is important for civil servants to be open and informed about the needs of citizens, to keep the procedures transparent and to obtain customer feedback. Local government communication is 
aimed at maximizing citizens' participation and involvement in the life of the local community, as well as promoting integration, trust and developing individuals' responsibility for their actions etc.; so education, information and motivation are very important (Smalec, 2015).

Knowledge of different communication opportunities for local authorities and community leaders can help to reduce potential conflicts. Involving citizens in decision-making encourages local people to make positive changes in their parishes and regions and increase their understanding of the decision-making process, for example, that it may be slow and may be subject to both laws and different administrative provisions. Citizen engagement enhances the possibility that the implemented projects or solutions will have wider public support and that more effective solutions will be found in mutual cooperation. Based on the knowledge of local communities and groups, practical and effective solutions are created; citizens' knowledge and skills in solving problems are supplemented; co-operation between people with different backgrounds takes place; groups of people who feel marginalized or not involved in development processes can gain more control over their lives and their own regions. When people from different parts of the region, from different localities work together, they often find much in common, create local networks, and create many different opportunities to discuss problems. Working together improves communication, understanding of the problems and their solutions, as people regularly express their anxiety / concern before communicating before the problems become too big or distorted (Bassler, Brasier, Fogle..., 2008). New information can be fed into communication through existing channels, such as the radio, bulletin boards at local cooperatives, stores, interpersonal networks etc. The internet may be used to support sustainable rural development; well-organized users' groups can access information relevant to local needs and realities (Melkote, 2009).

Besides above mentioned benefits for communicators, the essential expected result of participation is the reduction of social distance between communicators and listeners, between leaders and followers, thus promoting a fairer exchange of ideas, knowledge and experience. The ability to listen is crucial to communication between the various agents involved. The theorists put forward the following prerequisites for communicating public participation: "First, it is necessary for the public to participate effectively in the communication field; secondly, there is the design of a framework in which this can take place; and, thirdly, the media must enjoy professional autonomy, free of economic, political or whatever pressure" (Servaes, Malikhao, 2005). "Development means lifting up the spirit of a local community to take pride in its own culture, intellect and environment. Development aims to educate and stimulate people to be active in self- and communal improvements while maintaining a balanced ecology" (Servaes, 2008).

Summarizing the theoretical material, it can be concluded that communication between local governments and local people is considered an instrument that not only makes it easier to implement different projects and solve problems but also contributes to the development of the place and community.

Considering above mentioned, the aim of the article is to explore government-citizen communication in rural municipalities of Latvia from the viewpoint of local citizens. Tasks are related to describing of theoretical statements concerning governance-citizen communication in the light of sustainable development and analysing empirical information. Research questions are the following: 1) where do citizens acquire information about events and current developments in local 
municipalities? 2) what is people's assessment of the current communication with local authorities? 3) what should municipalities improve in their communication with citizens?

\section{Research results and discussion 1. Methodology and respondents`characteristics}

The article describes and analyses the results of the questionnaire "Use of natural and cultural environment in the regions" (National Research Programme for the period 2014-2017, project 5.2.8. "Cultural environment development, preservation of the nature diversity and urbanisation processes within the context of the balanced development of Latvia") on the communication of the population with the local governments. The total number of respondents is $498: 21.6 \%$ of them from Mazsalaca county, $32.5 \%$ - from Kraslava county, $21.8 \%$ - from Kandava county, $10 \%$ from Sabile town and $14.1 \%$ - from other counties of Latvia. Respondents' direct survey took place in July-November 2016 during the visits to local municipalities. Simultaneously, an internet survey was conducted using the portal "VisiDati.Iv". The study used a combined sample - $66.9 \%$ of respondents compiled the available sample - these respondents were questioned using the direct survey method on site. The rest - $33.1 \%$ of the respondents - completed the electronic questionnaire. Respondents by gender: $74 \%$ are women and $26 \%$ are men. The average age of respondents is 41 years, but in general the age of respondents varies from 14 to 89 years. After life in their place of residence, respondents are divided as follows: $43.6 \%$ of respondents have lived in their place of residence since birth, $34.2 \%$ of respondents moved more than 15 years ago, $12.6 \%$ of respondents moved from 5 to 15 years ago, and $9.6 \%$ of respondents moved less than 5 years ago. Regarding the respondents' occupation, it was possible to note several responses. The largest number of respondents - 30.0\% work in state / municipal institutions, $19.2 \%$ of respondents work in the private sector, $14.4 \%$ currently go to school or university, $10.1 \%$ are pensioners, $9.9 \%$ - self-employed persons, 6, $5 \%$ - housewives, $5 \%$ - unemployed and the smallest group of respondents are entrepreneurs $-4.9 \%$. The results of the survey were analysed by focusing on the common features of the communication without separate comparison by territorial units or between different categories of the population, drawing attention to the link between the sustainability of place development and communication.

\section{Analysis of quantitative data}

The study found out where the citizens of the municipality get information about events and topicalities in the municipality, as well as how often different sources of information are used.

Local people use different sources of information to keep up with the latest issues in their area. The total survey data confirms that people use a wide variety of media. Local government press releases ( $56.6 \%$ of respondents read them often or very often), regional newspapers (50\%), municipal websites $(50 \%)$ are used relatively often for information purposes, but the most important and most frequently used information channel is informal social networks communication with relatives, friends and acquaintances (69.3\%). There are less direct contacts with local government employees (19.1\% of respondents engage in them often or very often), following local government social media accounts (34\%), reading a message board (38.6\%) (Figure 1). 


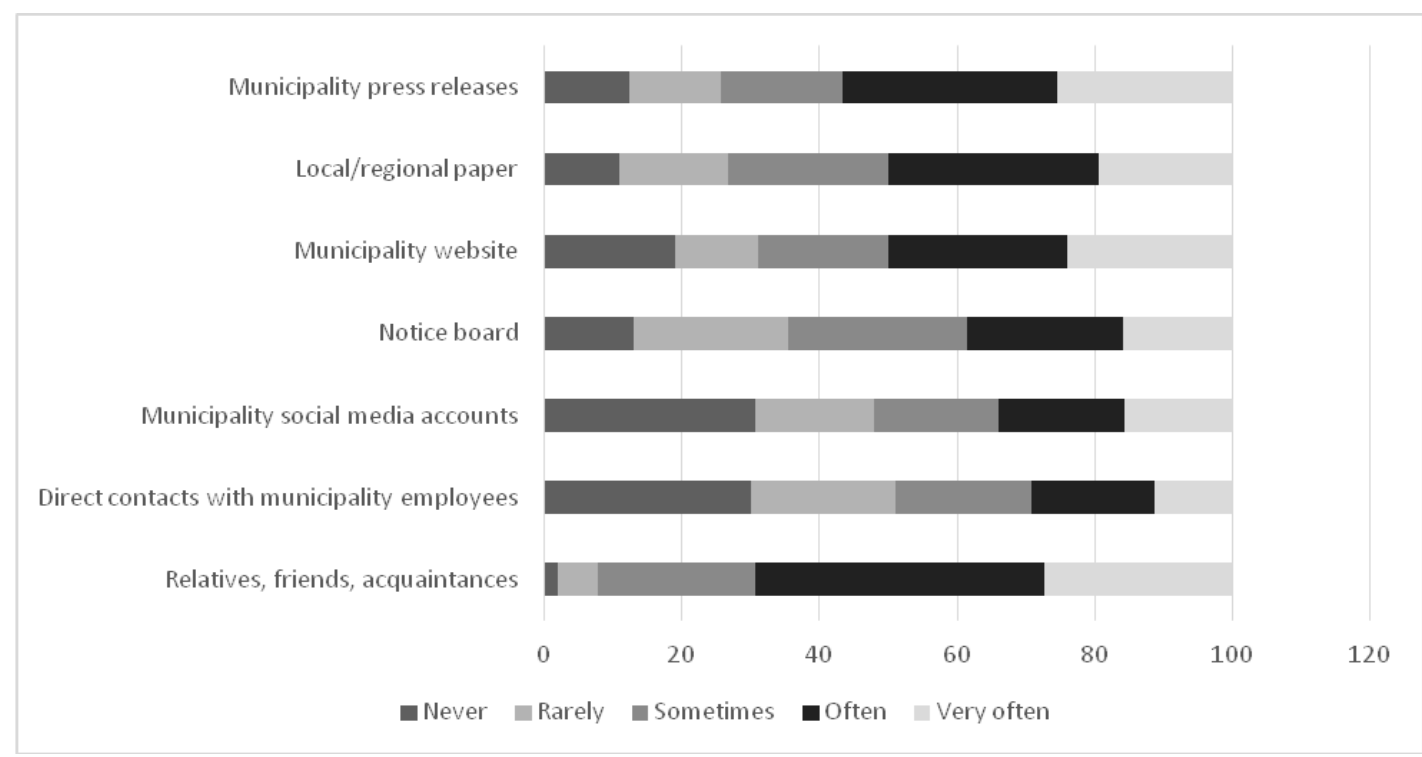

Source: author's calculations based on the survey results

Fig. 1. Frequency of use of various sources of information, \%

The respondents in the questionnaire were asked to assess the communication of the municipality with the population, using a scale of 1 to 5 , where 1 is "very weak" and 5 is "very good". In general, the average evaluation prevails: it is chosen by $39.0 \%$ of the respondents; communication is favourably evaluated by $34.5 \%$, very good - by $5.0 \%$, but as weak and very weak - by $21.5 \%$ of respondents (Fig. 2). Comparing the municipalities with each other, there is a difference in the assessment of the communication with the population. In Kandava municipality, there is a higher proportion of respondents who see municipal communication with the population as "weak" and "very weak"; in Mazsalaca municipality they make up $7.9 \%$ of respondents, Kraslava municipality - $19.3 \%$, and Kandava municipality $-36.3 \%$.

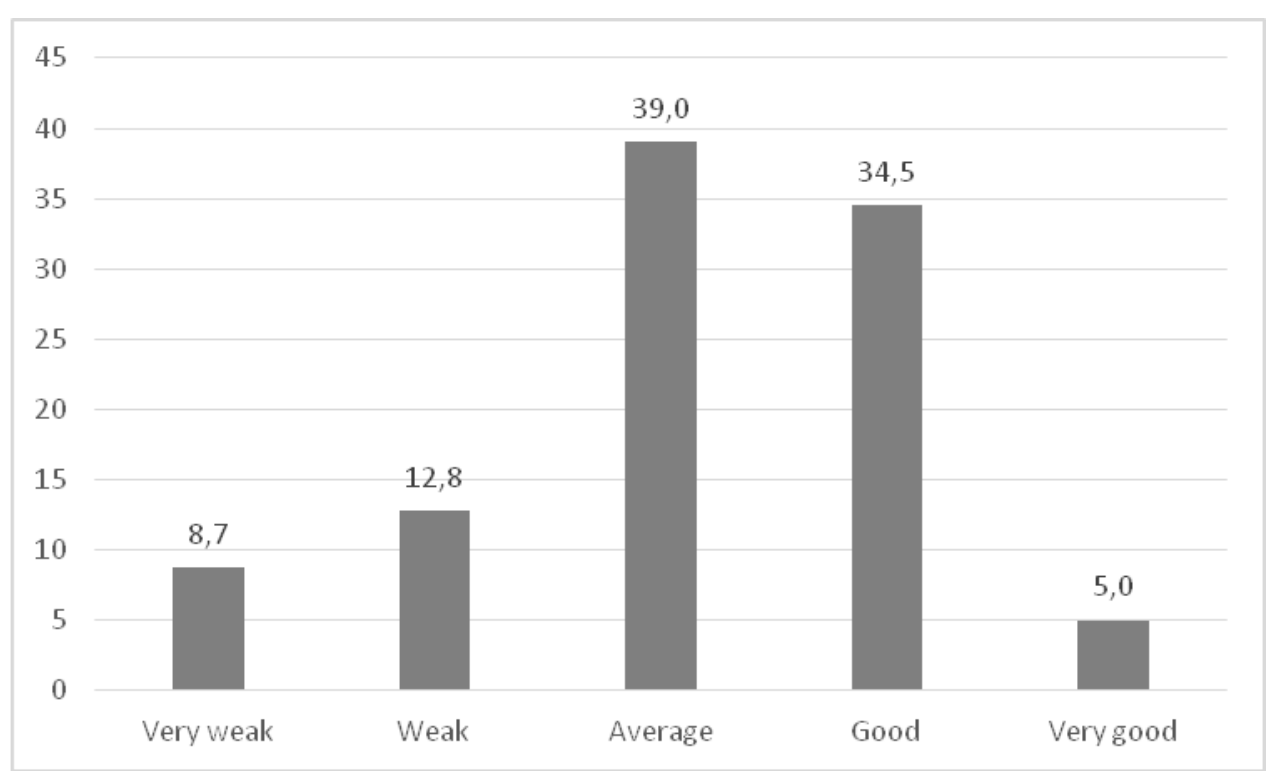

Source: author's calculations based on the survey results

Fig. 2. Assessment of municipal communication with citizens, \%

Similarly, in assessing their awareness of developments in the county and municipality, concerning the relevance of the content to the reader's needs (on the scale from 1-5) the dominating one is the rating "on average" (3.32 and 3.27), and the availability and reciprocity of 
the municipality to citizens' initiatives and problem-solving is generally evaluated as average (3.10).

Although numerical indicators suggest that citizens evaluate the communication with municipalities predominantly as satisfactory, the open question on what the municipality should improve in its communication with the population was answered by giving critical comments and suggestions.

\section{Analysis of qualitative data}

Having summarized the comments written by respondents to the open question "What should the municipality improve in communicating with the population", it can be concluded that this was a topical issue and the respondents' comeback to this question was high: out of 498 respondents, 245 provided their answers, although this was not intended as a mandatory question.

Communication can be analysed at the institutional level and at the individual level. Institutional communication is understood as the strategy and public image of local governments, how it positions its decisions and implemented actions, but the communication is not less important on a personal level when officials and local government employees interact with the citizens of the respective municipality. Consequently, the range of proposals addressed to the municipality is extensive, starting with the fact that there is no need to improve, because everything is satisfactory in this respect, and also expressing the opinion that the responsibility for obtaining the necessary information is to be assumed by the citizens themselves: "All those that want to find out something get the necessary information, and nothing stops them. But those that are not happy with things won't be happy even if the information is spoon-fed to them!" The other extreme view is to place all the responsibility for communication on the municipality: "I don't feel like the municipality is communicating to the people. It looks like each of the parties is on its own". For example, it is proposed that the municipality develop a vision for the development of the county and promote it among the population. Here, it must be kept in mind that the development vision for every county has already been developed and that citizens are also invited to create and discuss it, becoming active promoters of development, rather than passive beneficiaries or performers. By contrast, other respondents are aware of their impact on the development of the area, but they believe that the weakest link in the chain is the local government's reluctance to take active action. Based on several comments, it is easy to see the desire for meetings, think tanks, forums and other forms of meetings where citizens would feel like agents able to influence the local community. Citizens express a desire for real or "regular, targeted and meaningful" communication, rather than formal deliberations or deputy outreach meetings, which are just a formality; the meeting should not be only "to provide information to look better on paper, but also discuss things that pose problems, the areas where there are difficulties". It is interesting that the respondents recommend to the management to learn the experience of specific neighbouring municipalities, where, in their opinion, the communication of local government employees with the citizens is better organized. In general, the criticisms and suggestions made by the population give the impression that local civil society is more ready for open dialogue and bottom-up development than municipalities: "They should listen to the ideas of the people on the improvement in various areas, since the people can better tell how these problems could be prevented".

By studying the communication, other problems and situations that characterize rural municipalities have also been highlighted. For example, respondents in their comments express 
their suspicion about a certain vacuum of information or the lack of certain information, the domination of the personal ambitions of municipality deputies in relation to collective interests, the distancing of power from the local population after the administrative territorial reform.

Citizens' proposals also reveal a clear lack of understanding between the citizens and the employees of the municipality, which is expressed by some emotionally rich comments, for instance, "We must both talk and LISTEN, instead of: I am here, and this is how things will go [accents as in the original]!" This comment indicates possible exercising of power by the municipal government, which gives the people feeling of powerlessness. Citizens also remind that the municipality should take care of the image more directly among the local population, not against other municipalities: "The municipality should do something not to be so distant from its people". Overall, invitation to the municipality to listen to the views and needs of local people is very common in comments, which generally shows a gap between authorities and the public.

Along with the power aspect, for example, the recommendation "not to feel superior to the people of the region, then there will be good communication", the respondents call on the municipality to become one of the horizontal network agents in order to strengthen mutual cooperation and jointly decide on the development of the municipality. Thus, some respondents recommend placing information on the county website not only about municipal institutions, but also about companies and other organizations.

In the case of rural municipalities, the specifics of communication in rural communities cannot be underestimated, which has some advantages and disadvantages. Individual respondents point out to the employees of the municipality the breaches of confidentiality in the disclosure of personal information or emotional attitudes towards visitors. Consequently, informal, professional and ethical attitudes towards local people are expected from the employees of the municipality, or as one respondent writes, "they must study psychology" and learn the basics of mutual communication: "The municipality talks to the people, but lacks the skills to persuade them of their vision, so they end up "forcing" it on the people, which shows that people's opinions are not especially important". The lack of professionalism of municipality employees is highlighted by several respondents, especially in situations where citizens express criticism. Consequently, one of the proposals for improving communication is to give an opportunity to express an opinion anonymously. On the other hand, the fact that people in rural areas are well acquainted with each other can serve as a good starting point for mutual communication. Among the suggestions to the municipality, respondents mention the need of personal contact and personal involvement: "Sometimes the human factor must be taken into account and not the material advantage". The presence of a human factor is an indispensable part of the communication in the countryside, because it is what these people value the most: "The former head of administration was kinder, more accessible to people; this one is haughty". Respondents in this regard become municipality advisers, pointing out that "direct communication is best when you can talk it out. People want to have personal contact". Thus, in order to carry out the direct duties of rural municipalities and subordinated parish administrations, account must be taken of the actual needs of the citizens that are related to the form of communication.

An important part of the comments is the proposals that are not directly related to communication, such as "think more about young people" or "support for new entrepreneurs", which can also be interpreted as a consequence of insufficient communication in the past. In some 
cases, respondents point to other problems not solved in the county, considering that communication is a subordinate issue for the implementation of the local government's direct functions: "The only thing I need from the municipality is a road to get to work / home, but it's getting worse, sometimes inaccessible. Communication does not improve the road."

Among the constructive proposals to the municipality, there are recommendations to make more use of social networks, to make it possible to apply for news via e-mail, to communicate with local government employees electronically, to place information about meetings with local government employees in several public places, to provide answers to questions in the municipal information report: "In the past, there were registered letters and suggestions, questions from citizens that were answered publicly (by publishing) for everyone to see. At the moment, no suggestions and issues are being discussed and published", as well as to use text messages in mutual communication and to publish informative materials more often so that they do not lose their relevance. A valuable proposal is to organize cultural and educational events, which would also serve as a platform for communication on current affairs in the municipality. Respondents also reflect on their own responsibility in building communication and encourage citizens of the county to become "less shy, bolder and more active".

\section{Conclusions, proposals, recommendations}

1) Government-citizen communication in rural municipalities of Latvia is regarded as an up-todate, but insufficiently identified and evaluated tool for the development of people's involvement and place development processes;

2) Municipalities in rural areas use different communication channels, including modern solutions, but the analysis of the situation reveals some inconsistency with theoretical concepts and other research results, because the dominating communication model in rural municipalities in Latvia is "top-down" model, which is often based on power relations, is one-sided and formal. Municipalities generally do not have a citizen-client approach;

3) The gap in government-citizen communication is also confirmed by the increasingly limited opportunities for citizens to express their views on what is going on in the municipality, thus not encouraging feedback from the population, which is a prerequisite for participatory communication. At the same time, the results of the research reveal the local population as being active agents ready to engage in communication;

4) The use of informal social networks is dominant in the local community, which poses the risks that information may be incomplete or misleading; therefore, local authorities as important communication agents in the place development should take into account the specifics of communication in rural communities;

5) The analysis of the research results highlights not only the shortcomings in the communication process between municipalities and the population, but also a wider range of problems faced by rural municipalities in Latvia;

6) The authors recommend rural municipalities to become more aware of the importance of communication, to create horizontal communication with various social agents, thus promoting a common understanding of the objectives of the place development. 


\section{Bibliography}

1. Bassler, A., Brasier, K., Fogle, N., Taverno, R. ( 2008). Developing Effective Citizen Engagement: A How-To Guide for Community Leaders Developing Effective Citizen Engagement: A How-To Guide for Community Leaders. Retrieved: http://www.rural.palegislature.us/effective_citizen_engagement.pdf) Access: 27.01.2018.

2. Bruce, S., Yearley, S. (2016). The SAGE Dictionary of SOCIOLOGY. Retrieved: file:///E:/My \%20Documents/Downloads/sage-dictionary \%20(1).pdf Access: 10.01.2018.

3. Kagume, K. (2015). Leveraging Online Engagement in Rural Municipalities. Retrieved: https://era.library.ualberta.ca/files/9w0325881/2016-09\%20Author \%20Permission-MACTKagume \%20(1).pdf Access: 10.01.2018.

4. Lie, R., Servaes, J. (2015). Disciplines in the Field of Communication for Development and Social Change. Communication Theory 25 (2015) 244-258, International Communication Association. Retrieved: file:///E:/My \%20Documents/Downloads/Disciplines_in_the_field_of_Communicatio.pdf Access: 27.01.2018.

5. Mefalopulos, P. (2008). DEVELOPMENT COMMUNICATION SOURCEBOOK Broadening the Boundaries of Communication. The International Bank for Reconstruction and development/The World Bank. Retrieved: http://documents.worldbank.org/curated/en/752011468314090450/text/446360Dev0Comm1ns0handbook0 1PUBLIC1.txt) Access: 17.01.2018.

6. Melkote, S. (2009). Mass Media in Support of Sustainable Development. In Journalism and Mass Communication. Vol.II.220-237 pp. In Ed. Luthra R. Encyclopedia of Life Support Systems, EOLSS Publishers/UNESCO. Retrieved: https://books.google.Iv/books?id=0k7DDAAAQBAJ\&printsec=frontcover\&source=gbs_ge_summary_r\&cad= $0 \# \mathrm{v}=$ onepage\&q\&f=false. Access: 17.01.2018.

7. Servaes, J. ed. (2008). Communication for Development and Social Change. SAGE Publications India, 356 p.

8. Servaes, J. ed. (2013). Sustainability, Participation \& Culture in Communication: Theory and praxis. Chicago: Intellect - University of Chicago Press, 398 p.

9. Servaes, J., Malikhao, P. (2005) Participatory communication: the new paradigm? In Media and Glocal Change: Rethinking Communication for Development Chapter 5. 91-104 pp. Retrieved: http://biblioteca.clacso.edu.ar/clacso/coediciones/20100824064944/09Chapter5.pdf) Access: 17.01.2018.

10. Smalec, A. (2015), LOCAL GOVERNMENT OFFICES COMMUNICATION WITH RESPECT TO RESIDENTS OF NEW CONCEPT OF MANAGEMENT. Retrieved: http://www.toknowpress.net/ISBN/978-961-6914-130/papers/ML15-257.pdf Access: 17.01.2018 